\title{
Revealing water's secrets: deuterium depleted water
}

\author{
Vladyslav V Goncharuk, Alina A Kavitskaya, Iryna Yu Romanyukina and Oleksandr A Loboda*
}

\begin{abstract}
Background: The anomalous properties of water have been of great interest for generations of scientists. However the impact of small amount of deuterium content which is always present in water has never been explored before. For the first time the fundamental properties of deuterium depleted (light) water at $4^{\circ} \mathrm{C}$ and $20^{\circ} \mathrm{C}$ are here presented.

Results: The obtained results show the important role of the deuterium in the properties of bulk water. At $4^{\circ} \mathrm{C}$ the lowest value of the kinematic viscosity $\left(1.46 \mathrm{~mm}^{2} / \mathrm{s}\right)$ has been found for $96.5 \mathrm{ppm} \mathrm{D/H} \mathrm{ratio.} \mathrm{The} \mathrm{significant} \mathrm{deviation}$ in surface tension values has been observed in deuterium depleted water samples at the both temperature regimes. The experimental data provides direct evidence that density, surface tension and viscosity anomalies of water are caused by the presence of variable concentration of deuterium which leads to the formation of water clusters of different size and quantity.
\end{abstract}

Conclusions: The investigated properties of light water reveal the origin of the water anomalies. The new theoretical model of cluster formation with account of isotope effect is proposed.

Keywords: Deuterium depleted water, Surface tension, Viscosity, Water clusters

\section{Introduction}

For over thousand years water kept its secrets. At the first glance water seems to be one of the most simple and abundant substances, however in addition to $\mathrm{H}_{2} \mathrm{O}$ it has also $\mathrm{H}_{3} \mathrm{O}^{+}, \mathrm{OH}^{-}, \mathrm{HOD}$, and $\mathrm{OD}^{-}$moieties [1] which are in part responsible for the multifold of unusual properties. There have been numerous attempts to explain the anomalies of water (Pauling's, Robinson, Takahashi, Chaplin's two states model etc.) [2-7]. The most intriguing and discussed theory on the origin of water anomalies is the water cluster model [5]. The density inhomogeneities of $\sim 1 \mathrm{~nm}$ length-scale have been reported from the small-angle X-ray scattering measurements [8]. Conversely, the existence of density inhomogeneities in liquid water has been called into question recently [9]. However the attempts to interpret the $\mathrm{x}$-ray diffraction data to probe the molecular arrangement even in the first coordination shell of liquid water can not provide unambiguous structural information [10-12].

*Correspondence: o.a.loboda@iccwc.kiev.ua

A.V. Dumansky Institute of Colloid Chemistry and Chemistry of Water, National Academy of Sciences, Kyiv, Ukraine
At zero ${ }^{\circ} \mathrm{C}$ the ice structure has all hydrogens in a "bonded" state. With the gradual increase of temperature the number of broken water hydrogen bonds increases too. This process is accompanied by a decrease in the volume and an increase in the density. However, also the "competitive" process of thermal expansion should be considered, which operates in an opposite way (reduces the density). Below $4^{\circ} \mathrm{C}$, at atmospheric pressure the thermal expansion coefficient $\left(\alpha=(\delta \ln v / \delta T)_{P}\right)$ is negative. The magnitude of the $\alpha$ also reflects the correlations between the entropy and volume fluctuations. These fluctuations are positively correlated at the temperature above $4^{\circ} \mathrm{C}$ and anti-correlated below $4^{\circ} \mathrm{C}$ at which decrease in volume results in an corresponding increase in entropy value. In fact, upon the formation of open hydrogen bonded network the orientational contribution to the entropy is decreased which is instantly accompanied by a volume expansion [13]. With increasing temperature from $0^{\circ} \mathrm{C}$ to $4^{\circ} \mathrm{C}$, the effect of hydrogen bonds cleavage prevails over the thermal expansion, so the total volume decreases (large clusters break up into smaller clusters). The decrease in volume leads to an increase of density, which goes to a maximum at $4^{\circ} \mathrm{C}$. At this point the density increment held due to the cleavage of hydrogen bonds is 
balanced by the effect of thermal expansion which causes a decrease in density. At temperatures above $4^{\circ} \mathrm{C}$, the effect of thermal expansion prevails over the destruction of hydrogen bonds, resulting in the loss of the density $[6,7]$. Thus, one may assume that at the temperature range $0^{\circ}-4^{\circ} \mathrm{C}$ an increase of non-hydrogen bonded $\mathrm{H}$ atoms might occur due to the collapse of large supramolecular complexes into the small clusters. Reducing the size of the clusters would lead to the volume decrease which is inversely proportional to the density.

However none of the proposed models take into account isotope composition of water and therefore can not fully unravel the complexity of water. The physical properties of heavy water, water enriched with the deuterium and heavy-oxygen isotopes, are well-known [14-17]. The boiling and freezing points of such water are shifted from the relevant points of normal water. Heavy water is widely used in nuclear power reactors as a neutron moderator [18]. It has also been reported to be harmful for living beings and toxic for cells [19]. Fortunately the amount of deutereuted water molecules in normal water insignificantly small and is about $150 \mathrm{ppm}$.

The majority of science community neglects the concentration of heavy isotopes of protium in water and assumes that it consists of solely $\mathrm{H}_{2} \mathrm{O}$. In this work we investigate the effect of these small quantities of $\mathrm{D}_{2} \mathrm{O}$ in normal water by elaborating the extreme case of the deuterium depleted water i.e. light water. The prime purpose of the present research is to study the physical properties of light water. Experimental measurements in the absence of the deuterated water indirectly tell us how important is the content of $\mathrm{D}_{2} \mathrm{O}$ for the magnitude of physical constants. The list of published peer-reviewed research papers on the topic of light water is scarce (less than few dozens of papers) and almost limited to the effect of deuterium-depletion on living cells [20-22]. However to the best of our knowledge the fundamental physical properties of pure light water (below $150 \mathrm{ppm}$ ) have never been investigated. Therefore the overall aim of the work is to generalize the obtained knowledge in order to build up a comprehensive view on the organization of water.

\section{Results}

The density, kinematic viscosity and surface tension of water with varying amounts of deuterium obtained for the temperature regimes $4^{\circ}$ and $20^{\circ} \mathrm{C}$ are shown in Table 1 . The dilution of light water ( $2 \mathrm{ppm}$ ) by heavy water content up to $19 \mathrm{ppm}$ elevates the kinematic viscosity and surface tension, though the density does not change significantly. This effect is observed at the both temperatures, but is more profound at $4^{\circ} \mathrm{C}$. An increase in temperature leads to a significant reduction of the viscosity and surface tension values.
It is interesting to note how the small variations of $\mathrm{D}_{2} \mathrm{O}$ molecules (for example from 4 to $19 \mathrm{ppm}$ ) can affect the physical properties of the whole system. This effect becomes more pronounced as the temperature lowers, but diminishes or masked by other collective processes at $>150 \mathrm{ppm}$ and under conditions of the higher temperatures. With the increase of deuterated water molecules in the range of $19-97 \mathrm{ppm}$ the kinematic viscosity decreases from 1.5145 to $1.4627 \mathrm{~mm}^{2} / \mathrm{s}$, while the surface tension is almost constant $(77.58)$ at $4^{\circ} \mathrm{C}$. The densities of the water samples with deuterium contents ranging from 2 to $97 \mathrm{ppm}$ do not deviate at both temperature values $4^{\circ} \mathrm{C}$ and $20^{\circ} \mathrm{C}$. Substantial deviations of the surface tension and kinematic viscosity are observed in water probes with a $\mathrm{D} / \mathrm{H}$ ratio of $146 \mathrm{ppm}$. At $4^{\circ} \mathrm{C}$ the kinematic viscosity sharply increases and constitutes $1.5896 \mathrm{~mm}^{2} / \mathrm{s}$. The surface tension's decrease pattern pertains to water at $4^{\circ}$ and $20^{\circ} \mathrm{C}$ as well, though it is more characteristic at $4^{\circ} \mathrm{C}$. The deuterium concentration less than $2 \mathrm{ppm}$ has not be achieved experimentally to date.

\section{Discussion}

As is expected the density of light water does not show any appreciable change due to the very small quantity of deuteriated water at the $1-150 \mathrm{ppm}$ level. Surface tension (ST) on the other hand is the result of weak intermolecular interactions in liquid water. The decrease of ST with increasing temperature is usually associated with a decrease in density due to the increase of intermolecular distances. However, it should be noted, all experimental measurements indicate that the changes of ST far exceed the corresponding change in density. For example, in the temperature range from 0 to $100^{\circ} \mathrm{C}$, the volume is changed by $4 \%$ while ST is reduced by $22 \%$. This significant change of ST can not be explained only by the change in the density or the interaction of individual molecules, but can be tackled on the basis of the cluster model. With increasing temperature, the average cluster size decreases. Also, the increase in temperature enlarges the intercluster distances, which entails a reduction of unbound $\mathrm{O}$ $\mathrm{H}$ groups in the surface layer, that causes a decrease of ST.

At a constant isotopic content the size of the clusters depends on the temperature. The gradual increase of the temperature also leads to an increase of intercluster distances and the breaking of large clusters into the smaller ones which reflects an increase of free hydrogen bond O$\mathrm{H}$ groups. However at selected constant temperatures, the fraction of NHB $\mathrm{H}$ atoms varies as a function of the concentration of deuterium, which is manifested in a change in the characteristics of the viscosity and the surface tension. This change in the physicochemical properties of water means that the deuterium introduced into the system affect the distribution of the bound and unbound 
Table 1 Kinematic viscosity, surface tension and density of deuterium depleted (Superlight), Semilight, Normal, Semiheavy and Heavy water samples studied at $4^{\circ} \mathrm{C}$ and $20^{\circ} \mathrm{C}$

\begin{tabular}{|c|c|c|c|c|c|c|c|}
\hline \multirow{2}{*}{$\begin{array}{l}\text { Water } \\
\text { sample }\end{array}$} & \multirow{2}{*}{$\begin{array}{c}\text { Deuterium } \\
\text { content }\end{array}$} & \multicolumn{2}{|c|}{ Kinematic viscosity, $\mathrm{mm}^{2} / \mathrm{s}$} & \multicolumn{2}{|c|}{ Surface tension, $\mathrm{mN} / \mathrm{m}$} & \multicolumn{2}{|c|}{ Density, $\mathrm{g} / \mathrm{cm}^{3}$} \\
\hline & & $4^{\circ} \mathrm{C}$ & $20^{\circ} \mathrm{C}$ & $4^{\circ} \mathrm{C}$ & $20^{\circ} \mathrm{C}$ & $4^{\circ} \mathrm{C}$ & $20^{\circ} \mathrm{C}$ \\
\hline \multirow{2}{*}{ Superlight } & 2 ppm & $1.5458 \pm 0.0017$ & $0.9923 \pm 0.0017$ & $76.27 \pm 0.01$ & $73.93 \pm 0.01$ & $1.0001 \pm 0.00015$ & $0.9979 \pm 0.00015$ \\
\hline & 4.2 ppm & $1.5179 \pm 0.0017$ & $0.9626 \pm 0.0017$ & $76.39 \pm 0.01$ & $73.93 \pm 0.01$ & $0.99950 \pm 0.00015$ & $0.9982 \pm 0.00015$ \\
\hline \multirow{4}{*}{ Semilight } & 18.9 ppm & $1.5145 \pm 0.0017$ & $\mathrm{n} / \mathrm{a}$ & $77.58 \pm 0.01$ & $\mathrm{n} / \mathrm{a}$ & $0.99995 \pm 0.00015$ & $0.9999 \pm 0.00015$ \\
\hline & 37 ppm & $1.4863 \pm 0.0017$ & $\mathrm{n} / \mathrm{a}$ & $77.58 \pm 0.01$ & $\mathrm{n} / \mathrm{a}$ & $0.99980 \pm 0.00015$ & $\mathrm{n} / \mathrm{a}$ \\
\hline & $41.3 \mathrm{ppm}$ & $1.4900 \pm 0.0017$ & $\mathrm{n} / \mathrm{a}$ & $77.34 \pm 0.01$ & $\mathrm{n} / \mathrm{a}$ & $0.99989 \pm 0.00015$ & $0.9999 \pm 0.00015$ \\
\hline & 96.5 ppm & $1.4627 \pm 0.0017$ & $\mathrm{n} / \mathrm{a}$ & $77.58 \pm 0.01$ & $\mathrm{n} / \mathrm{a}$ & $1.00040 \pm 0.00015$ & $1.0004 \pm 0.00015$ \\
\hline \multirow{2}{*}{ Normal } & 144.7 ppm & $1.5746 \pm 0.0017$ & $1.0075 \pm 0.0017$ & $75.49 \pm 0.01$ & $72.58 \pm 0.01$ & $1.00027 \pm 0.00015$ & $0.9975 \pm 0.00015$ \\
\hline & 145.6 ppm & $1.5896 \pm 0.0017$ & $1.0057 \pm 0.0017$ & $74.87 \pm 0.01$ & $72.75 \pm 0.01$ & $1.00030 \pm 0.00015$ & $1.0001 \pm 0.00015$ \\
\hline \multirow{2}{*}{ Semiheavy } & $52 \%$ & $1.6502 \pm 0.0017$ & $1.0534 \pm 0.0017$ & $74.83 \pm 0.01$ & $70.39 \pm 0.01$ & $\mathrm{n} / \mathrm{a}$ & $\mathrm{n} / \mathrm{a}$ \\
\hline & $53 \%$ & $1.6514 \pm 0.0017$ & $1.0862 \pm 0.0017$ & $74.87 \pm 0.01$ & $70.39 \pm 0.01$ & $1.05850 \pm 0.00015$ & $1.0532 \pm 0.00015$ \\
\hline \multirow{2}{*}{ Heavy } & $90.98 \%$ & $1.7813 \pm 0.0017$ & $1.1968 \pm 0.0017$ & $70.08 \pm 0.01$ & $67.08 \pm 0.01$ & $1.1052 \pm 0.00015$ & $1.1052 \pm 0.00015$ \\
\hline & $99.96 \%$ & $1.7500 \pm 0.0017$ & $1.274 \pm 0.0017$ & $69.93 \pm 0.01$ & $67.80 \pm 0.01$ & $1.1040 \pm 0.00015$ & $1.1042 \pm 0.00015$ \\
\hline
\end{tabular}

$\mathrm{OH}$ groups. The question arises is how? From the data conducted for experiments with a light water one sees that the surface tension has a maximum value for a content of deuterium $\leq 96.5 \mathrm{ppm}$. The atoms of deuterium having mass twice of the protium make more stronger $\mathrm{O}-\mathrm{D}$ bonds than $\mathrm{O}-\mathrm{H}$ bonds. Our theoretical calculations show stable spherical structures with encapsulated guest molecules [23]. We anticipate that the deuterium atoms form the core of the cluster, around which the light molecules are arranged symmetrically in a strictly defined mosaic order. Upon reduced concentration of deuterium $(\leq 155 \mathrm{ppm})$ the clusters can be expected of a larger size than in extreme cases of pure light and heavy water, which means fewer NHB $\mathrm{H}$ atoms and hence a greater surface tension. Because the larger clusters have a lower "mobility" in comparison with small water clusters, then the dynamic viscosity must also to increase with increasing cluster size and the registered deviations of kinematic viscosity values must be in consistency with the corresponding deviations of dynamic viscosity at the condition of constant density of water.

Dilution of the light water with the heavy water content should lead to the increase of the cluster size. This trend reaches its maximum at $\mathrm{D} / \mathrm{H} \sim 150 \mathrm{ppm}$ inherent to the normal water. Then, however, the further deuterium atoms compete with each other in the process of cluster formation, which leads to a decrease of the clusters size under the excess of the deuterium isotope. Let's try to answer the question what is really behind this mechanism? In our earlier work [23] we investigated the homologous series of icosahedral water clusters with various inclusions $\left(\mathrm{CO}_{2}, \mathrm{CH}_{4},\left(\mathrm{H}_{2} \mathrm{O}\right)_{n}\right)$ (see Figure 1). Among these series the smallest spherical cluster, which can accommodate, for instance a deuterated hydronium cation, is dodekahedra (b) with 20 water molecules composed from 12 pentamers (a). Next to it is a cluster (c) consisting of 100 water molecules on the surface of which there are 30 unbound hydrogen atoms. If 4 additional deuterated active centers appear then the cluster can break down into five basic dodecahedra, which together will produce 50 unbound hydrogen atoms (NHB $\mathrm{H}$ atoms). The next largest cluster (d) contains 280 water molecules and only $60 \mathrm{NHB} \mathrm{H}$ atoms. The collapse of such a cluster into 14 elementary subclusters will make possible the formation of $140 \mathrm{NHB} \mathrm{H}$ atoms. Thus an increase in deuterium content leads to a decrease in the size of the clusters, which in its turn leads to an increase of NHBs, and the last in our opinion, causes a decrease of surface tension and viscosity under conditions of constant temperature.

When the ice melts at $0^{\circ} \mathrm{C}$ into the liquid water it absorbs an energy of $80 \mathrm{cal} / \mathrm{g}$ [24]. This energy $80 \mathrm{cal} / \mathrm{gm}$ does not lead to an increase in temperature. We may speculate that the major part of this energy is spent for cleavage of $13 \%$ of the hydrogen bonds in the structure of ice, while the $87 \%$ of the bonds may remain intact. Therefore, the cluster sizes must be huge in order to accommodate $87 \%$ hydrogen bonds "inherited" from the structure of ice. Small clusters mean a large number of broken hydrogen bonds. The experimental data display the decrease in the size of the clusters with the increase in temperature [25]. Also theoretical calculations $[26,27]$ show the broadening of oxygen-oxygen radial distribution function upon temperature increase. Apparently the elongation of inter-cluster distance contributes to the water density decrease. The increase in inter-cluster distances with increasing temperature also leads to a decrease in the number of $\mathrm{NHB} \mathrm{H}$ atoms per unit area and, consequently, ST reduction. 


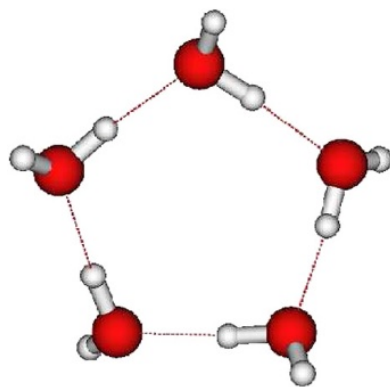

a

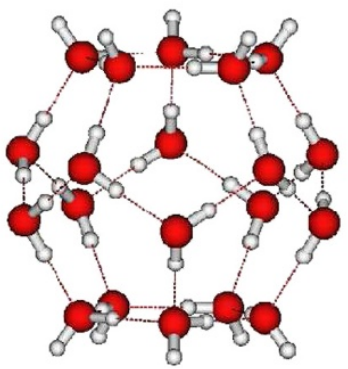

b

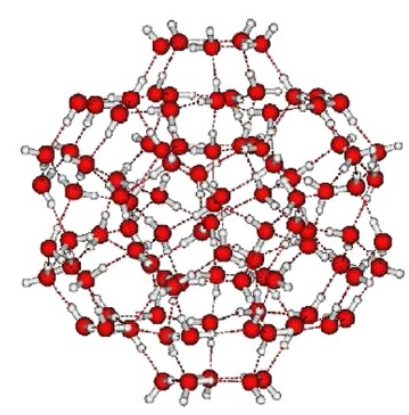

C

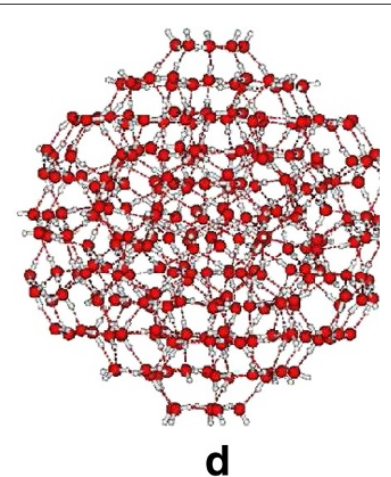

d

Figure 1 Pentamer coordinated water network: (a) cyclic pentamer, (b) $5^{12}$ dodecahedral cluster $\left(\mathrm{H}_{2} \mathrm{O}\right)_{20}$, (c) homological icosahedral $\left(\mathrm{H}_{2} \mathrm{O}\right)_{100}$ and (d) $\left(\mathrm{H}_{2} \mathrm{O}\right)_{280}$ clusters.

Finally, considering the role of isotope effect on physical properties of water one can not neglect the $\mathrm{O}^{18} / \mathrm{O}^{16}$ ratio. Based on results obtained from our investigation we may conclude that the concentration of the heavy isotope of oxygen is closely related with the concentration of deuterium. The increase of deuterium connected with the increase of ${ }^{18} \mathrm{O} /{ }^{16} \mathrm{O}$ ratio: at $4 \mathrm{ppm}$ of $\mathrm{D} / \mathrm{H}$ the $\mathrm{O}^{18} / \mathrm{O}^{16}$ is $910 \mathrm{ppm}$; at $52,53 \% \mathrm{D} / \mathrm{H}$ the ${ }^{18} \mathrm{O} /{ }^{16} \mathrm{O}$ concentrations are 1479,1552 ppm correspondingly. This indirectly signifies the bound character of these two heavy isotopes. The simultaneous increase or decrease of ${ }^{18} \mathrm{O}$ and ${ }^{2} \mathrm{H}$ quantities become possible during formation of covalent bonds between them which give appearance to the $\mathrm{D}_{2}{ }^{18} \mathrm{O}$, $\mathrm{HD}^{18} \mathrm{O}$ molecules. It should be noted that these molecules make hydrogen bonding stronger than the ${ }^{1} \mathrm{H}_{2}{ }^{16} \mathrm{O}$ or $\mathrm{HD}^{16} \mathrm{O}$ species due to the lower energy of zero point vibrational level. In our opinion the heavy isotopes of oxygen when they participate in cluster formation play a static role and make an additional contribution to the stability of the cluster while the deuterium atoms govern the whole process of water structuring and hence causes the qualitative changes of physicochemical properties of water.

For the first time the experimental studies have been conducted on deuterium depleted water. The anomalous properties of water at $4^{\circ} \mathrm{C}$ are found to be due to the heavy isotope of protium, which is responsible for the water cluster formation. The developed conception of determining factor of deuterium is in a good agreement with the experimental data obtained for the water samples with various deuterium content at the same conditions. The represented model provides a comprehensive assessment of the "isotope composition - water structure" relations.

\section{Materials and methods}

Water samples with the $\mathrm{D} / \mathrm{H}$ ratio $2.0 ; 4.2 ; 18.9 ; 37.0$; $96.5 ; 144.7 ; 145.615 \mathrm{ppm}$ have been obtained by vacuum distillation and purchased from Clarte company (Moscow,
Russia). The heavy water $90.98 \%$ has been produced by "Cinta Crystal" Ltd. (Kyiv, Ukriane) in accordance with the standard specification (TU) 95-1893-89; the 99.96\% heavy water purchased from MERCK company (Darmstadt Germany). The water samples with the $52 \%$ and $53 \%$ content of deuterium have been obtained by dilution of $90.8 \%$ heavy water using light water ( $4.2 \mathrm{ppm})$. The semiheavy water $(52,53 \% \mathrm{D} / \mathrm{H})$ has been studied due to the maximum content of HDO molecules formed in the self exchange equilibrium reaction $\mathrm{H}_{2} \mathrm{O}+\mathrm{D}_{2} \mathrm{O} \leftrightarrow 2 \mathrm{HDO}$. Analysis of the isotopic composition of water has been performed using modified mass-spectrometer (MI-1201) at the Institute of Geochemistry of the Environment, National Academy of Sciences.

The modified stalagmometric method is used for the measuring surface tension. The surface tension is calculated according to the formula:

$$
\sigma=\frac{V g}{2 \pi R}\left(\frac{\rho}{n}\right)
$$

where volume $V$ corresponds to $n$ drops, which are released from the stalagmometer with the radius of stalagmometer tube $\mathrm{R}, \rho$ is the density of the liquid. In order to exclude the factor of the stalagmometer dependence, the drops number of standard $\left(\mathrm{n}_{x}\right)$ and investigated $\left(\mathrm{n}_{o}\right)$ liquids is counted. If the liquid with known surface tension is used then the surface tension of the other liquid can be calculated from the equation:

$$
\sigma_{x}=\sigma_{o} \frac{n_{o} \rho_{x}}{n_{x} \rho_{o}}
$$

Methodology for the obtaining density, kinematic viscosity parameters can be found elsewhere [28]. The measurements are carried out in a sealed box, maintaining the temperature of $4 \pm 0.1^{\circ}, 20 \pm 0.05^{\circ}$ at a relative humidity of $60 \%$ and a pressure of $750 \mathrm{mmHg}$. All experiments are carried out above the dew point.

The relative mean errors are $0.11 \%$ (kinematic viscosity), $0.01 \%$ (surface tension) and $0.015 \%$ (density). 
Competing interests

The authors declare no competing interests.

\section{Authors' contributions}

VG designed and supervised the project; AK and IR carried out the experiments; VG, AK and OL analyzed the data; OL simulated the model and wrote the manuscript. All authors discussed the results and commented on the manuscript. All authors read and approved the final manuscript.

Received: 14 February 2013 Accepted: 28 May 2013

Published: 17 June 2013

\section{References}

1. Kakiuchi M: Distribution of isotopic water molecules, H2O, HDO, and D2O, in vapor and liquid phases in pure water and aqueous solution systems. Geochim Cosmochim Acta 2000, 64:1485-1492.

2. Frank HS, Quist AS: Pauling's model and the thermodynamic properties of water. J Chem Phys 1961, 34:604-611.

3. Robinson GW, Cho $\mathrm{CH}$, Gellene Gl: Refractive index mysteries of water J Phys Chem B 2000, 104:7179-7182.

4. Cho $\mathrm{CH}$, Singh S, Robinson GW: Water anomalies and the double-well Takahashi model. Chem Phys 1998, 232:329-341.

5. Chaplin MF: A proposal for the structuring of water. Biophys Chem 2000, 83:211-221.

6. Khan A, Khan MR, Khan MF, Khanam F: A liquid water model that explains the variation of surface tension of water with temperaure. Jpn J Appl Phys 2001, 40:1467-1471.

7. Khan A, Khan R, Khan MF, Khanam F: A cluster model explaining quantitatively the anomalous variation of density of water with temperature. Chem Phys Lett 1997, 266:473-480.

8. Huang C, et al: The inhomogeneous structure of water at ambient conditions. Proc Natl Acad Sci USA 2009, 106:15214-15218.

9. Soper AK, Teixeira J, Head-Gordon T: Is ambient water inhomogeneous on the nanometer-length scale? Proc Natl Acad Sci USA 2010, 107:E44.

10. Wernet $P h$, et al: The structure of the first coordinationshell in liquid water. Science 2004, 304:995-999.

11. Smith JD, et al: Unified description of temperature-dependent hydrogen-bond rearrangements in liquid water. Proc Natl Acad SCi USA 2004, 102:14171-14174.

12. Huang C, et al: Reply to Soper et al.: Fluctuations in water around a bimodal distribution on local hydrogen-bonded structural motifs. Proc Natl Acad Sci USA 2010, 107:E45.

13. Debenedetti PG: Supercooled and glassy water. J Phys: Condens Matter 2003, 15:R1669-R1726.

14. R EK: Physical and chemical properties of heavy water. Nature 1934 134:504-504

15. Steckel F, Szapiro S: Physical and chemical properties of heavy water. Trans Faraday Soc 1963, 59:331-343.

16. Kudish Al, Wolf D, Steckel F: Physical properties of heavy-oxygen water. Absolute viscosity of $\mathrm{H} 2180$ between 15 and 35C. J Chem SOC, Faraday Trans 1972, 68:2041-2046.

17. Straub J, Rosner N, Grigull U: Surface tension of normal and heavy water. Warme- und Stoffubertragung 1980, 13:241-252.

18. Miller Al, van Alstyne HM: Heavy water: a distinctive and essential component of CANDU. AECL 1994, 10962:1-11.

19. Goncharuk W: Science About Water. Kyiv: Naukova Dumka; 2010: 1-512.

20. Avila DS, Somlyai G, Somlyai I, Aschner M: Anti-aging effects of deuterium depletion on $\mathrm{Mn}$-induced toxicity in a $\mathrm{C}$. elegans model. Toxicol Lett 2012, 211:319-324.

21. Cong FS, et al: Deuterium-depleted water inhibits human lung carcinoma cell growth by apoptosis. Exp Ther Med 2010, 1:277-283.

22. Krempels K, Somlyai I, Somlyai G: A retrospective evaluation of the effects of deuterium depleted water consumption on 4 patients with brain metastases from lung cancer. Integr Cancer Ther 2008, 7:172-181.

23. Loboda O, Goncharuk V: Theoretical study on icosahedral water clusters. Chem Phys Lett 2010, 484:144-147.

24. Ohmine I: Liquid water dynamics: collective motions, fluctuation, and relaxation. J Phys Chem 1995, 99:6767-6776.

25. Goncharuk W, Orekhova EA, Malyarenko W: Influence of temperature on water clusters. J Wat Chem Tech 2008, 30:80-84.
26. Lazaridis T, Karplus M: Orientational correlations and entropy in liquid water. J Chem Phys 1996, 105:4294-4316.

27. Shaik MS, Liem SY, Popelier LA: Properties of liquid water from a systematic refinement of a high-rank multipolar electrostatic potential. J Chem Phys 1996, 132:174504.

28. Goncharuk V, et al: Physicochemical properties and biological activity of the water depleted of heavy isotopes. J Wat Chem Tech 2011, 33:8-13.

doi:10.1186/1752-153X-7-103

Cite this article as: Goncharuk et al.: Revealing water's secrets: deuterium depleted water. Chemistry Central Journal 2013 7:103.

\section{Publish with ChemistryCentral and every scientist can read your work free of charge}

"Open access provides opportunities to our colleagues in other parts of the globe, by allowing anyone to view the content free of charge."

W. Jeffery Hurst, The Hershey Company.

- available free of charge to the entire scientific community

- peer reviewed and published immediately upon acceptance

- cited in PubMed and archived on PubMed Central

- yours - you keep the copyright

Submit your manuscript here:

http://www.chemistrycentral.com/manuscript/<smiles>c1ccccc1</smiles>

Chemistry Centra 